\title{
Proposal for Qualification of Gas-Generating Radioactive Payloads for Transportation within a Type B Package
}

by

T. K. Houghtaling

Westinghouse Savannah River Company

Savannah River Site

Aiken, South Carolina 29808

A document prepared for 2002 ASME PRESSURE VESSELS AND PIPING CONFERENCE at Vancouver, British Columbia, , Canada from 8/5/2002 - 8/9/2002.

\section{DOE Contract No. DE-AC09-96SR18500}

This paper was prepared in connection with work done under the above contract number with the U.S. Department of Energy. By acceptance of this paper, the publisher and/or recipient acknowledges the U.S. Government's right to retain a nonexclusive, royalty-free license in and to any copyright covering this paper, along with the right to reproduce and to authorize others to reproduce all or part of the copyrighted paper. 
This document was prepared in conjunction with work accomplished under Contract No. DE-AC09-96SR18500 with the U. S. Department of Energy.

\section{DISCLAIMER}

This report was prepared as an account of work sponsored by an agency of the United States Government. Neither the United States Government nor any agency thereof, nor any of their employees, makes any warranty, express or implied, or assumes any legal liability or responsibility for the accuracy, completeness, or usefulness of any information, apparatus, product or process disclosed, or represents that its use would not infringe privately owned rights. Reference herein to any specific commercial product, process or service by trade name, trademark, manufacturer, or otherwise does not necessarily constitute or imply its endorsement, recommendation, or favoring by the United States Government or any agency thereof. The views and opinions of authors expressed herein do not necessarily state or reflect those of the United States Government or any agency thereof.

This report has been reproduced directly from the best available copy.

Available for sale to the public, in paper, from: U.S. Department of Commerce, National Technical Information Service, 5285 Port Royal Road, Springfield, VA 22161, phone: (800) 553-6847, fax: (703) 605-6900

email: orders@ ntis.fedworld.gov

online ordering: http://www.ntis.gov/support/index.html

Available electronically at http://www.osti.gov/bridge

Available for a processing fee to U.S. Department of Energy and its contractors, in paper, from: U.S. Department of Energy, Office of Scientific and Technical Information, P.O. Box 62, Oak Ridge, TN 37831-0062,

phone: (865)576-8401,

fax: (865)576-5728

email: $\underline{\text { reports@ adonis.osti.gov }}$ 


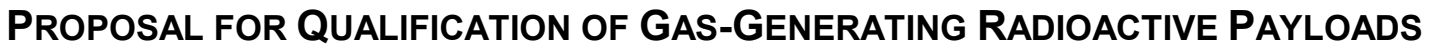 FOR TRANSPORTATION WITHIN A TYPE B PACKAGE
}

\author{
T. K. Houghtaling \\ Westinghouse Savannah River Company
}

\begin{abstract}
Characterization data describing radioactive materials (RAM) in storage are likely those associated with the processes that produced the materials or with the mission for which they were produced. Along with impurity data, often absent or unknown as a result of post-processing storage environment is moisture content. Radiolysis of moisture may lead to a hydrogen flammability hazard within a closed volume such as a storage can or a transportation package. This paper offers a practical means of qualifying payloads of unknown moisture content for shipment within Type B packaging, while supporting the DOE program to maintain radworker dose as low as reasonable achievable (ALARA). Specifically, the paper discusses part of a qualification program carried out at the Savannah River Site for onsite shipment of legacy RAM within the DDF-1 package. The DDF-1 is an onsite-only prototype of the currently certified 9975 package. Measurement of storage-can lid bulge can provide an upper bound for pressure within a storage can. Subsequent belljar testing can measure the rate of gas leakage from a storage can. These actions are shown sufficient to ensure that the performance of the 9975 containment vessels can accommodate 1) the deflagration energy from flammable gas mixtures within Normal Conditions of Transport, and 2) the consequences of a detonation shock wave within Hypothetical Accident Conditions.
\end{abstract}

\section{INTRODUCTION}

Within the Department of Energy (DOE) complex, radioactive materials can be housed for significant periods of time in storage vessels before incorporation into new missions. Often, missions require inter-site shipment of the radioactive materials (RAM) within the complex. Shipment over public highways is often necessary and requires a RAM packaging certified for the specific payload. In support of package certification, the proposed payload must be characterized, and its behavior under regulatory requirements must be evaluated and shown acceptable, including flammable gas concentrations below lower flammability limits. This paper describes how RAM payloads of unknown moisture content can be qualified for onsite transfer at the Savannah River Site (SRS) in the DDF-1 package and how the same process could be applied to offsite shipment. The core issue discussed is how to limit flammable gas concentrations and how to accommodate the corresponding consequences of combustion within a transportation package.

\section{ONSITE TRANSFER AT THE SRS - BACKGROUND}

As part of the Defense Nuclear Facilities Board (DNFSB) Recommendation 94-1, plutonium-bearing RAM in interim storage at the SRS is being consolidated and stabilized for longterm storage in accordance with DOE's 3013 standard. The RAM in question has been in storage for more than a decade, and the moisture content is not known. Hence, the potential exists for generating flammable gas mixtures by radiolysis of sorbed moisture $\left(2 \mathrm{H}_{2} \mathrm{O} \rightarrow 2 \mathrm{H}_{2}+\mathrm{O}_{2}\right)$.

Knowledge of the processes that produced the RAM is generally beneficial to understanding gas generation potential. Calcination at high temperature for a suitable period of time can reduce the surface area of RAM particles and thereby limit moisture re-adsorption during storage. Given a favorable calcination pedigree, steady state moisture content can be bounded and with it the potential for flammable gas generation. ${ }^{[1]}$ In the absence of a favorable processing history, the case discussed here, two paths forward have been considered.

One path is application of recombiner technology wherein liberated hydrogen and oxygen molecules are recombined with the help of a catalyst to form water that is then retained by an absorbing agent. ${ }^{[2]}$ Other chemical agents called getters can combine irreversibly with free hydrogen and be included with the recombiner as a defense in depth measure. This will be discussed in a separate paper.

The other path forward, the subject of this paper, is direct measurement of gas generation, development of acceptable thresholds for accumulation of flammable gasses and development of shipper-friendly means of implementing the limits.

Preventing accumulation of flammable gasses within a package 
is certainly preferred, but may not always be achievable. Hence, the possibility of ignition, however unlikely, must be acknowledged. For flammable gas combustion within a package to be deemed an acceptable event, the consequences of the event must be shown not to compromise containment integrity. The containment vessels within the packaging must be shown capable of sustaining the slow pressure pulse from deflagration and capable of sustaining the supersonic shock wave associated with a transition from deflagration-todetonation.

In theory, detonation can be prevented by controlling the geometry within the local environment of a containment vessel (restricting inter-component gap dimensions), thereby eliminating nucleation of the event. In fact, DOE has approved this method of preventing detonation for application within the 9975 package. In practice however, the detonation-preventing gap size (minimum detonation cell size) is often as small as a few millimeters and control of geometry can be a challenge to implement without impeding loading and unloading operations.

\section{ONSITE TRANSFER AT THE SRS - ENABLING FEATURES}

The plutonium-bearing RAM stored at the SRS is housed typically in the following can/bag/can arrangement. The RAM resides inside a slip-lid can to which the lid is secured by tape. The slip-lid can is enclosed inside a heat-sealed plastic bag to facilitate contamination control. The bagged can is placed inside a food-pack can to which the closure lid is then crimp sealed by an ordinary mechanical can-closure device. Other configurations exist wherein the RAM was bagged in plastic before entering the slip-lid can. In each configuration, the inner can is assumed to leak freely.

The materials are heads, tails or excess from various weapons programs around the DOE complex. Often the isotope mixtures are known within process limits along with chemicals or impurities relevant to the processes. From this information and from analysis of material samples, the potential can be established for chemical reactions among chemical constituents under transport conditions. Conceivably, elevated temperature associated with transportation could promote chemical behavior not active during vault storage.

For onsite transfer at the SRS, DOE Order 460.1A permits implementation of administrative controls in place of explicit compliance with the Hazardous Materials Regulations (HMR) as long as equivalent safety is achieved. Hence, the potential for chemical reactions within the package stimulated by elevated temperatures can be reduced or eliminated by procedure. Approved operating procedures for the DDF-1 package disallow exposure to direct sunlight except briefly during placement within a conveyance that also shades the packages from insolation. The action described is similar to operation of the Safe Secure Trailer (SST).

The plutonium-bearing RAM stored at the SRS has been in place for over a decade and demonstrated to be at steady state by an SRS surveillance program. Hence, four scenarios can describe the relevant states of storage cans. ${ }^{1}$

1. No lid bulge, no gas generation, no can leakage

2. No lid bulge, significant gas generation, gross can leakage

3. Lid bulge, significant gas generation, no can leakage

4. Lid bulge, significant gas generation, some can leakage

Gas accumulation may occur within a can, within the containment vessel or both. Clearly, gas generation (pressure) and accumulation of flammable gasses (combustion) are issues that must be resolved as part of payload qualification for onsite transfer.

A surveillance program for measuring storage can lid deflection has been in place at SRS since 1994, and studies have been carried out to assess the sensitivity and precision of the measuring system. Recently a set of curves was established relating measured deflection to internal pressure for the different styles of food-pack cans used at the SRS. ${ }^{[3]}$ The curves account for variations in measurement statistically and provide a $95 \%$ confidence that the actual pressure is less than that associated with the deflection measurement. Internal pressure as low as three psig is discernable.

Out-gassing from storage cans may be collected and measured by means of a surrogate PCV. Specifically, a close-fitting belljar outfitted with appropriate temperature and pressure instrumentation is used at the SRS to measure out-gassing behavior. ${ }^{[4]}$ By logging pressure change in the belljar over a suitable period of time, a leak rate can be determined for each storage can tested.

The belljar is double-sealed and operated much like a packaging containment vessel. Leak-tightness of the belljar hardware is first demonstrated, then prior to measuring the outgassing from a storage can, assembly of the belljar is verified by leak-testing its closure. Although the influence of diurnal temperature variation can be reduced out of the data, the belljar is placed inside an environmental chamber to minimize this effect. Within the environmental chamber, the temperature is maintained at a chosen level $\pm 1^{\circ} \mathrm{F}$. For the onsite transfer campaign discussed here, that temperature is $100^{\circ} \mathrm{F}$, matching the highest temperature occurring within the SRS storage vaults. This temperature was chosen for belljar testing because without insolation, the temperature of the local environment within the package would not rise significantly higher than this and therefore, could not trigger unknown chemical reactions.

1 The case wherein the lid is not bulged but dished by a partial vacuum inside the can is not addressed here, because the associated flammable gas hazard is bounded by the other scenarios. 
In retrospect, belljar testing of the storage cans could have been carried out at a higher temperature to match the local containment environment within the package under regulatory insolation. Favorable results there would have demonstrated accommodation of regulatory thermal NCT.

Out-gassing data in conjunction with lid-deflection data provide sufficient information to establish the maximum period of time a PCV may remain sealed for onsite transfer of its payload. This test-qualification process is part of the safety basis for onsite transfer of RAM-storage cans within the DDF-1 packaging.

\section{DDF-1 PACKAGE}

The DDF-1 is a prototype of the 9975 packaging, which is currently certified by the DOE for offsite shipment of up to 4.4 $\mathrm{kg}$ of plutonium metal or $5.0 \mathrm{~kg}$ of plutonium oxide. The DDF-1 name is an SRS nomenclature that represents a

Drum packaging with
$\underline{\text { Double containment vessels qualified for }}$
$\underline{\text { Fissile payloads with nominal volume of }}$
$\underline{\mathbf{1}}$ gallon.

The DDF-1 drum uses a standard bolt-nut-ring closure, while the 9975 design has incorporated a bolted-flange closure. In addition, the DDF-1 incorporates slightly heavier lead shielding than the 9975 design. Other differences between the two packagings are insignificant.

Derived from the 9975, the DDF-1 is also a double containment package. A schematic representation of the DDF-1 is shown in Figure 1. The radioactive contents (plutonium metal or oxide) are housed typically within two nested metal cans as a handling convenience. However, the DOE 3013 storage canister can also serve this purpose. A typical arrangement of payload cans inside the PCV is shown in Figure 2. The handling containers (payload cans) are placed into the primary containment vessel (PCV), and the PCV is placed into the secondary containment vessel (SCV). Both containment vessels are made of stainless steel and closed via screw top lids. Elastomer O-rings provide "leak tight" seals for each vessel. A layer of lead surrounding the two nested containment vessels provides radiation (gamma) shielding. A cane fiberboard overpack nearly five inches thick surrounds the lead and serves as both structural and thermal insulation. Finally, a 35-gallon stainless steel drum encloses and protects the fiberboard.

Maximum allowable pressures within the PCV and SCV under regulatory Normal Condition of Transport (NCT) are 900 psig and 800 psig, respectively. Under Hypothetical Accident Conditions (HAC), the allowable static limit pressures are 5500 psig and 5000 psig, respectively, based on a 5\% strain limit. While the containment vessels are robust, the closures are exceptionally robust. Hydrostatic testing of a PCV to failure required a pressure over $7500 \mathrm{psig}$. The cylindrical portion of the vessel wall ruptured, but the closure remained secure throughout the test. ${ }^{[5]}$

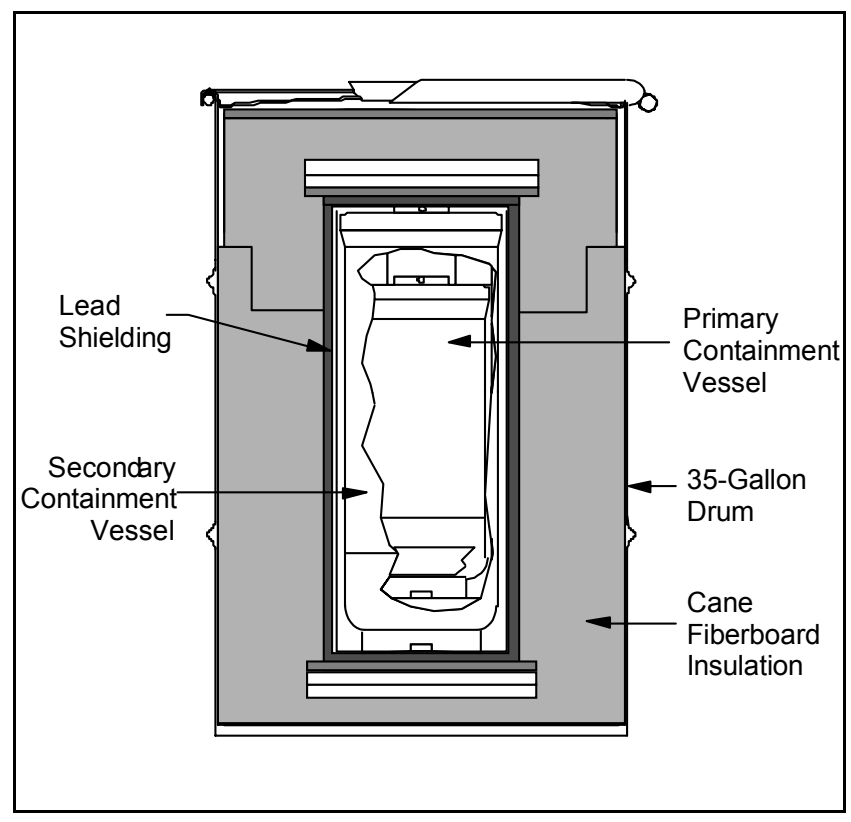

Figure 1 - Illustration of the DDF-1 Package

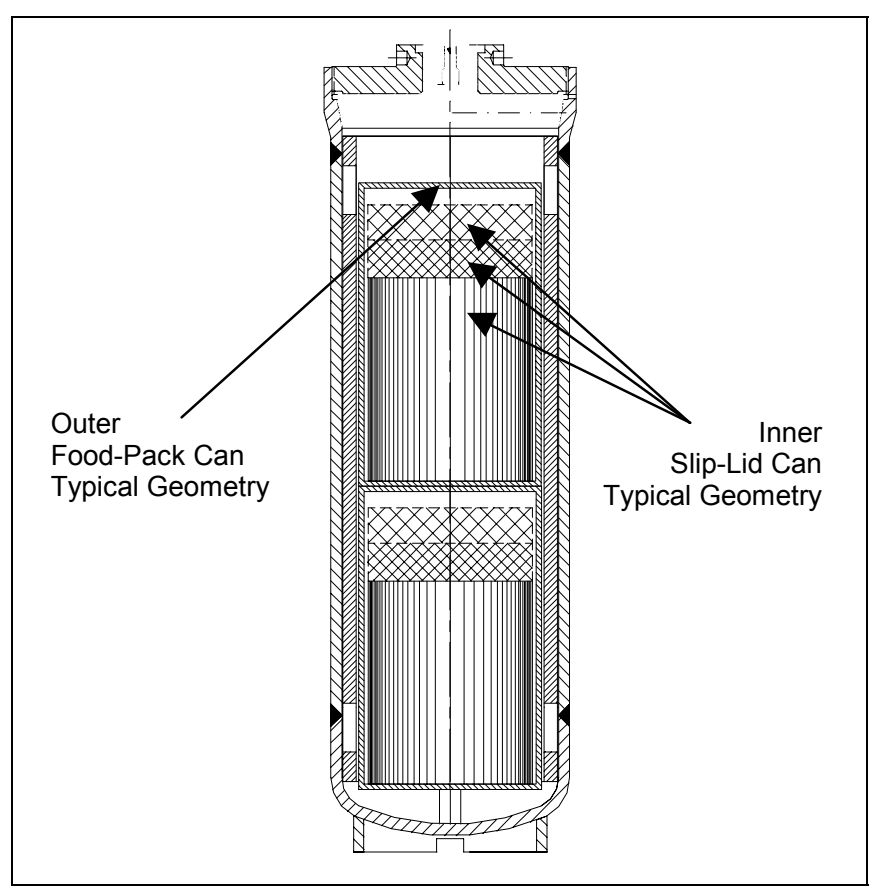

Figure 2 - Typical Arrangement of Payload Cans within the DDF-1 PCV

\section{ONSITE TRANSFER AT THE SRS - THE EVALUATION}

Assuming a gas-generating payload, a shipper-friendly packaging evaluation would seek to maximize the time the 
package could remain sealed for transport. This should be true for flammable gas accumulation as well as for pressure accumulation.

Toward that end, the containment vessels of the DDF-1 packaging were analyzed structurally. The maximum pressure capacities were established in accordance with Section III of the ASME Boiler and Pressure Vessel Code for NCT and Code Case 584 for HAC. Knowing both NCT and HAC capabilities of the containment vessels, the maximum allowable consequences of flammable gas combustion (deflagration and detonation) can be back calculated. From the consequences of combustion, the maximum allowable initial conditions can be established.

The food-pack cans storing the RAM have done so for over a decade and pressures sustained by the cans are at steady state. The pressurized gasses within the cans are assumed to be stoichiometric mixtures of hydrogen and oxygen and to occupy $100 \%$ of the can volume (solid contents are assumed to displace zero volume). Clearly, these are very conservative assumptions.

\section{Normal Conditions of Transport}

Not surprisingly, the consequences of a detonation event (a supersonic shock wave from a deflagration-to-detonation transition (DDT)) are more severe than the consequences of pure deflagration. Hence, detonation of flammable gasses within the food-pack cans sets the maximum allowable initial conditions within the food-pack cans. See the Hypothetical Accident Conditions section for discussion.

Worst case deflagration is evaluated as follows. Assume each of two sets of food-pack cans is at thermal equilibrium inside the DDF-1 under non-solar NCT temperature and pressurized to the maximum permitted by the HAC (detonation) evaluation. Assume also that both sets of cans release their confined gasses slowly (isothermally) into the PCV, raising the pressure outside the cans but not changing the average temperature outside the cans. Assume continued generation and release of hydrogen and oxygen from the food-pack cans until the pressure gradient from inside the cans to outside the cans is reduced to the pressure gradient sustained while in the storage vault. Assume the gas mixture is then ignited and burns to completion.

Deflagration is a slow process relative to the natural frequencies of the DDF-1 containment vessels, and the pressure pulse will build too slowly to excite a dynamic resonance. Therefore, no reduction in static pressure capacity is necessary to account for dynamic behavior of the vessels.

The maximum deflagration pressure is calculated via the SRS proprietary KABOOM computer code. The code models the chemistry and thermodynamics of hydrogen-air combustion $\left(\mathrm{H}_{2}+1 / 2 \mathrm{O}_{2}+\mathrm{xN}_{2} \rightarrow\right.$ combustion products). Equilibrium composition of the reaction products is dependent on temperature and pressure, parameters initially unknown. Hence, a numerical solution and a computer code are necessary.
The code calculates pressure peaks, but not pressure-time profiles, and accounts for: dissociation of water vapor into hydroxide, molecular hydrogen and molecular oxygen; dissociation of molecular hydrogen, molecular oxygen and molecular nitrogen; and the reaction that forms nitrous oxide.

Nitrogen presence from the air trapped inside the PCV at the time of vessel closure will dilute the combustibility of the total gas mixture and reduce the peak temperature of deflagration. However, though nitrogen will not burn, it may contribute significantly to the total number of moles of heated gas and thereby influence the maximum deflagration pressures.

At the SRS for example, low-heat plutonium scrap materials were qualified for onsite transfer in the DDF-1 package by a combination of lid-deflection and belljar measurements. Maximum deflagration pressure results from complete combustion (without detonation) at the maximum allowable pre-detonation conditions. These conditions and deflagration results within the PCV and within the SCV are calculated by the KABOOM code and given in Table 1.

Table 1 - Maximum Non-Solar NCT Pressures

\begin{tabular}{||c|c|c||}
\hline Condition & $\begin{array}{c}\text { PCV Pressure } \\
\left(\mathrm{psig} \text { at } 122^{\circ} \mathrm{F}\right)\end{array}$ & $\begin{array}{c}\text { SCV Pressure } \\
\left(\mathrm{psig} \text { at } 105^{\circ} \mathrm{F}\right)\end{array}$ \\
\hline Static Design Pressure & 900 & 800 \\
\hline $\begin{array}{c}\text { Non-Solar End-Of- } \\
\text { Transfer MNOP }\end{array}$ & 17.9 & 14.6 \\
\hline $\begin{array}{c}\text { Associated Peak } \\
\text { Deflagration Pressure }\end{array}$ & 252 & 226 \\
\hline
\end{tabular}

SCV pressure values assume leakage from the PCV into the SCV.

b Assumes two cans sustaining maximum DDT-based pressure leak slowly (isothermally) into the PCV and continue to generate $\mathrm{H}_{2}$ and $\mathrm{O}_{2}$, producing a pre- combustion pressure within the PCV that if detonated via DDT would generate the vessel limit pressure.

c Assumes two cans sustaining maximum DDT-based pressure leak completely into the PCV, continue to generate $\mathrm{H}_{2}$ and $\mathrm{O}_{2}$ and leak freely into the SCV producing a pre-combustion pressure within the $\mathrm{SCV}$ that if detonated via DDT would generate the vessel limit pressure.

d Assumes complete combustion of generated $\mathrm{H}_{2}$ and $\mathrm{O}_{2}$ in PCV air (no DDT) at end-of-transfer MNOP.

e Assumes complete combustion of generated $\mathrm{H}_{2}$ and $\mathrm{O}_{2}$ in SCV air (no DDT) at end-of-transfer MNOP.

Compared to allowable NCT pressures of 900 psig and 800 psig for the PCV and SCV, respectively, these deflagration events are sustainable under NCT and thereby do not compromise package safety.

\section{Hypothetical Accident Conditions}

Assuming a pressurized, stoichiometric mixture of hydrogen and oxygen (see Normal Conditions of Transport section), detonation must be addressed. Direct ignition of a detonation is 
not credible, since it would require the energy of a high explosive. However, a deflagration to detonation transition (DDT) is a credible means of ignition for a sufficiently small detonation cell size. If the presence of a detonable cell size within the containment vessels cannot be precluded, the consequences of a detonation shock wave must be evaluated.

The maximum credible pressure spike is developed from the scenario wherein DDT occurs after 50 weight percent of the gasses has been consumed, ${ }^{[6]}$ and the pressure is applied to portion of the vessel surface area. The maximum allowable pressure from a DDT event is limited to the dynamic limit pressure of the associated containment vessel.

Dynamic limit pressures for the containment vessels were established by considering the frequency of the maximum detonation spike conjunction with the natural frequencies of the vessels. Structural resonance achievable by dynamic loading of either containment vessel was quantified by evaluating the influence of pressure spikes of varying time durations. A dynamic amplification factor of $1.41^{2}$ was established ${ }^{[7]}$ as worst case and applied to the limit pressure from the static structural evaluation. The resulting dynamic limit pressures for the PCV and for the SCV are 3900 psig and 3550 psig, respectively.

Conceivably, a DDT event could occur

1. Inside a food-pack can

2. Within the PCV

3. Within the SCV

Consider first a DDT event within a food-pack can that is pressurized by an undiluted stoichiometric mixture of hydrogen and oxygen (no air). The maximum allowable initial conditions within a food-pack can are those that yield a detonation pressure spike equal to the PCV limit pressure.

For example, from the SRS low-heat plutonium scrap materials, the average gas temperature within a single maximum-heat can associated with non-solar NCT is $158^{\circ} \mathrm{F}$. The associated detonation spike can be calculated by the KABOOM computer code. Detonation of gasses at this temperature (via DDT) will yield the PCV's dynamic limit pressure if the can is initially at 15.3 psig. Hence, up to this pressure at $158^{\circ} \mathrm{F}$, a detonation (via DDT) within a food-pack can will not compromise PCV containment performance.

Consider next a DDT event within the PCV after pressurization by continuous generation and leakage of stoichiometric hydrogen and oxygen from the food-pack can(s) into the airfilled annular volume of the PCV.

2 The dynamic amplification factor can vary between one and two to account for the level of resonance between the structure and the impulse.
For example, from the SRS low-heat plutonium scrap materials, the average temperature of gasses inside the PCV but outside the food-pack can $(\mathrm{s})$ is $122^{\circ} \mathrm{F}$. Again, detonation behavior of this gas mixture can be calculated by the KABOOM computer code after establishing the nitrogen fraction. The maximum allowable pressure of this gas mixture within the PCV is 17.9 psig. Hence, up to this initial pressure at $122^{\circ} \mathrm{F}$, the effects of a detonation (via DDT) outside the food-pack cans but within the PCV will not compromise PCV containment performance.

However, if the pressurized gasses within the PCV were released into the SCV before detonation, the mixture would be reduced in both temperature and pressure and diluted further with nitrogen from air contained within the SCV. Consider a DDT event within the SCV after it is pressurized by continuous generation and leakage of stoichiometric hydrogen and oxygen from the food-pack can(s) into the PCV and slowly (isothermally) released into the air-filled annular volume of the SCV. This situation is not similar to absence of the PCV, since mixing of PCV gasses with SCV gasses is prevented. Working backward from the SCV's dynamic limit pressure, we can identify maximum allowable initial conditions within the SCV as those that yield detonation pressure spike equal to the limit pressure of the vessel.

For example, from the SRS low-heat plutonium scrap materials, the average air temperature within the SCV for a single maximum-heat load can and non-solar NCT is $105^{\circ} \mathrm{F}$. Once again, detonation behavior of this gas mixture can be calculated by the KABOOM computer code. The maximum allowable pressure of this gas mixture within the SCV is 14.6 psig. Up to this initial pressure at $105^{\circ} \mathrm{F}$, the effects of a detonation (via DDT) within the SCV will not compromise SCV containment performance. The results of the detonation evaluation are summarized in Table 2.

Note that the food-pack cans house the source of gas generation and will always be at a pressure that is equal to or higher than the pressure within the annular volume of the PCV surrounding the cans. This means that for the pre-combustion pressure within the PCV to reach the 17.9-psig value given in Table 2, the pressure of a detonable hydrogen and oxygen mixture within the food-pack cans would have to exceed its maximum allowable value. Therefore, only those conditions within the food-pack cans are relevant to the maximum allowable detonation pressure (from a DDT event) within the PCV. As a result, the pressure within the PCV (outside the food-pack cans) must be limited accordingly. This means the maximum allowable PCV pressure must be limited to a value that yields a pressure gradient no less than the pressure gradient sustained by the cans in storage. A lower through-the-can-seal pressure gradient would permit pressure within the can to accumulate beyond its allowable limit. 
Table 2 - Maximum HAC Pressures

\begin{tabular}{|c|c|c|c|}
\hline \multicolumn{2}{|l|}{ Condition } & $\begin{array}{c}\text { PCV } \\
\text { Pressure } \\
\text { (psig) }\end{array}$ & $\begin{array}{c}\text { SCV } \\
\text { Pressure } \\
\text { (psig) }\end{array}$ \\
\hline \multicolumn{2}{|c|}{ Static Limit Pressure ${ }^{a}$} & 5500 & 5000 \\
\hline \multicolumn{2}{|c|}{ Dynamic Limit Pressure $^{b}$} & 3900 & 3550 \\
\hline DDT Location & $\begin{array}{c}\text { Initial } \\
\text { Pressure } \\
\text { (psig) }\end{array}$ & \multicolumn{2}{|c|}{$\begin{array}{c}\text { Peak Detonation } \\
\text { Spike }^{\mathrm{c}}\end{array}$} \\
\hline $\begin{array}{c}\text { Inside Food-Pack Can at } \\
158^{\circ} \mathrm{F} \\
\quad \mathrm{N}_{2} \text { absent, }+ \\
\text { Stoich. } \mathrm{H}_{2} \& \mathrm{O}_{2}\end{array}$ & 15.3 & 3900 & $\mathrm{n} / \mathrm{a}$ \\
\hline $\begin{array}{l}\text { Inside PCV at } 122^{\circ} \mathrm{F} \\
\text { (Leaking Food-Pack } \\
\text { Cans): } \\
\mathrm{N}_{2} \& \mathrm{O}_{2} \text { normal } \\
\text { vessel air, }+ \\
\text { Stoich. } \mathrm{H}_{2} \& \mathrm{O}_{2}\end{array}$ & 17.9 & 3900 & $\mathrm{n} / \mathrm{a}$ \\
\hline $\begin{array}{l}\text { Inside } \mathrm{SCV} \text { at } 105^{\circ} \mathrm{F} \\
\text { (Leaking Food-Pack } \\
\text { Cans and leaking PCV): } \\
\\
\mathrm{N}_{2} \& \mathrm{O}_{2} \text { normal } \\
\text { vessel air, }+ \\
\text { Stoich. } \mathrm{H}_{2} \& \mathrm{O}_{2}\end{array}$ & 14.6 & $\mathrm{n} / \mathrm{a}$ & 3550 \\
\hline
\end{tabular}

a Based on minimum vessel wall dimensions and 5\% hoop strain.

b Based on application of Dynamic Amplification Factor of 1.41.

c DDT after 50 weight \% of the combustible gas mixture has been burned by deflagration.

d DDT evaluation for the SCV assumes the PCV displaces gas and supports isothermal gas-leakage behavior.

For example, from the SRS low-heat plutonium scrap materials, pressure within the food-pack cans is at steady state, because of the length of time the cans have been in storage. Food-pack cans showing less than $15.3 \mathrm{psig}$ at $158^{\circ} \mathrm{F}$ are candidates for packaging and onsite transfer. However, gas generation may still be ongoing at the rate of leakage from the can(s), and pressurization of a sealed PCV must not allow the pressure within the food-pack cans to exceed the 15.3 psig limit established for them.

Maximum allowed measures of generated/leaked gasses are presented in Table 3. Again assuming a slow isothermal process, starting with a food-pack can pressurized to $15.3 \mathrm{psig}$ at $158^{\circ} \mathrm{F}$, the maximum allowable amount of gas generation/leakage is $126 \mathrm{~cm}^{3}$ at the average temperature of the air outside the cans within the PCV, $122^{\circ} \mathrm{F}$. Starting with foodpack can(s) at a lower pressure, the allowable amount of gas generation/leakage increases as shown in the table. The last column of the table lists the maximum allowable gas-generation volumes at standard temperature and pressure for convenient comparison to belljar data.

Table 3 - Allowed Gas Generation/Leakage

\begin{tabular}{|c|c|c|c|}
\hline \multicolumn{2}{|c|}{$\begin{array}{c}\text { Steady State Pressure } \\
\text { within Food-Pack Cans }\end{array}$} & \multicolumn{2}{|c|}{$\begin{array}{c}\text { Total Gas } \\
\text { Generation/Leakage } \\
\text { from Food-Pack Cans }\end{array}$} \\
\hline $\begin{array}{l}\text { In Storage } \\
\text { (Psig at } \\
100^{\circ} \mathrm{F} \text { ) }\end{array}$ & $\begin{array}{l}\text { In Package } \\
\text { (Psig at } \\
\left.158^{\circ} \mathrm{F}\right)\end{array}$ & $\begin{array}{l}\text { Accumulated } \\
\text { in PCV } \\
\left(\mathrm{Cm}^{3} \text { at } 122^{\circ} \mathrm{F}\right. \\
\text { and psig) }\end{array}$ & $\begin{array}{c}\text { STP } \\
\left(\mathrm{Cm}^{3} \text { at } 68^{\circ} \mathrm{F}\right. \\
\text { and } 0.0 \mathrm{psig})\end{array}$ \\
\hline 12.5 & 15.3 & $126 @ 2.8$ & 136 \\
\hline 12.0 & 14.8 & $178 @ 3.3$ & 198 \\
\hline 9.0 & 11.5 & $448 @ 6.3$ & 580 \\
\hline 6.0 & 8.14 & $650 @ 9.3$ & 963 \\
\hline 3.0 & 4.83 & $808 @ 12.3$ & 1346 \\
\hline 0.0 & 1.52 & $934 @ 15.3$ & 1729 \\
\hline
\end{tabular}

Temperature is steady state based on 3-watt heat load and non-solar NCT.

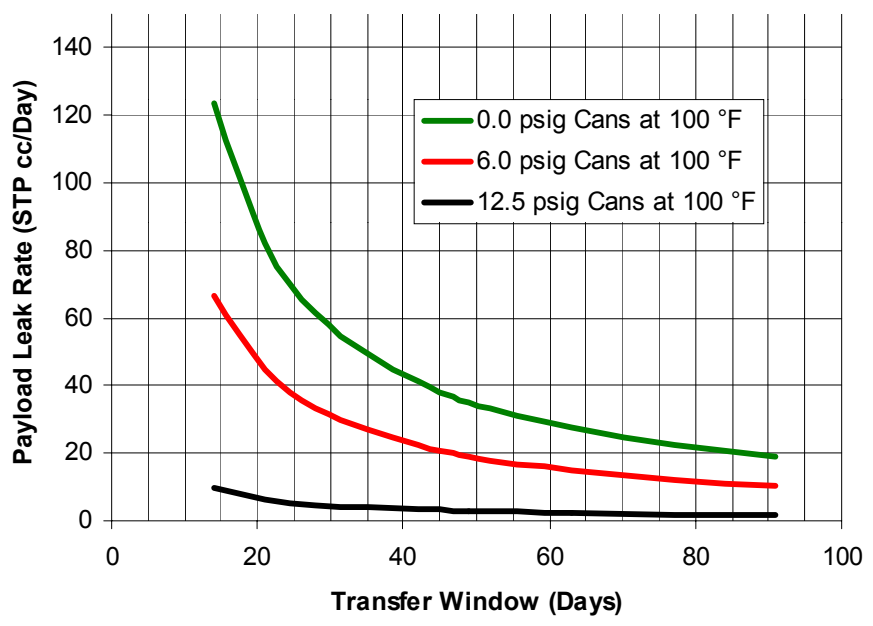

Figure 3 - Onsite Transfer Window for Pressurized Leaking Food-Pack Cans

Measurement of food-pack can pressures and measurement of food-pack can leak rates permits development of the maximum allowable time the containment vessels may remain sealed for onsite transfer. Figure 3 relates the total leak rate per package payload (normally two sets of food-pack cans), to maximum allowable time frame for transportation. The curves represent food-pack cans sustaining no pressure, sustaining a low but easily measurable pressure and sustaining the maximum allowable pressure. In practice, uncertainties associated with the canning process and with the lid-bulge response to internal pressure prevent utilization of the zero-pressure curve.

Consider a single food-pack can housing SRS low-heat plutonium scrap materials (and an empty can as dunnage). Assume the heat load is maximum allowed and the can pressured to $6.0 \mathrm{psig}$ at $100^{\circ} \mathrm{F}$ (in the storage vault or in the belljar test apparatus). For an onsite transfer window of 30 days, the leak rate from the can must be less than 31 STP 
cc/day. At the end of the transfer window, the can will have accumulated the maximum allowed pressure of 15.3 psig (at $158^{\circ} \mathrm{F}$ within the package).

If two cans are to be packaged, the first to reach its maximum allowable pressure governs the transportation window.

\section{ONSITE TRANSFER AT THE SRS - CONCLUSIONS}

A challenge of qualifying RAM of unknown moisture content for packaging and transportation onsite at the SRS was met as follows.

RAM residing in food-pack cans has been in storage at the SRS for over a decade and shown by surveillance to be at steady state. Gasses generated by radiolysis of unquantified moisture and accumulated within confinement vessels (food-pack cans) were assumed conservatively to be stoichiometric mixtures of hydrogen and oxygen. Gasses accumulated within containment vessels were assumed diluted by air present at the time the package was loaded. Both deflagration and detonation (via DDT) of the gas mixtures were considered and the consequences of the events were evaluated.

The structural and containment capacities of the DDF-1 containment vessels determined the maximum allowable detonation (from a DDT event) within the package as a credible accident condition. Assuming complete combustion (without DDT), the maximum deflagration within the package was evaluated as an off-normal event but within the non-solar NCT performance capability of the DDF-1 package. The worst-case detonation event (via DDT) occurs inside a food-pack can. Combustion energy outside of the food-pack cans is reduced significantly by nitrogen dilution from air trapped within the vessels at the time of loading.

Enforcement of the maximum allowable pressure within the food-pack cans was carried out in part by measuring can-lid deflections. Accounting for uncertainties associated with the can closure process and with the lid stiffness, a pressure of three psig is discernable by lid-deflection measurement.

To ensure that the maximum allowed pressure within a foodpack can is not exceeded, accumulation of pressure within the PCV is limited to the value that yields the pressure gradient sustained by the can in vault storage. Measurement of leak rates from the food-pack cans permits time-dependent calculation of gas accumulation within the PCV. Hence, a maximum allowable time frame for transportation may be established for each payload. The transportation window ensures that the consequences of flammable gas combustion will remain in compliance with the containment requirements applicable to the payload.

In summary, maximum normal operating pressure (MNOP), worst case deflagration pressure and worst case shock wave from transition from deflagration to detonation were calculated conservatively, compared to allowable values and shown to be acceptable for onsite transfer at the SRS. Avoidance of handson work to characterize and possibly re-can the RAM supports the DOE program to keep radworker dose as low as reasonably achievable (ALARA).

\section{RECOMMENDATIONS FOR APPLICATION TO SHIPMENTS IN COMMERCE}

The following discussion identifies by section title the major differences between onsite transfer at the SRS and shipment in commerce over public highways. Specifically addressed are those package performance features or payload behaviors that did not need evaluation for the SRS example.

\section{Influence of Regulatory Thermal NCT}

The transportation environment at the SRS is controllable in that packaging-related influences such as insolation can be prevented administratively as permitted in DOE Order 460.1A. Offsite shipments do not enjoy these privileges and must comply with the HMR explicitly. Hence, regulatory NCT must be used to determine the local thermal environments within a loaded package. Belljar testing of leak rates from food-pack cans (or other handling-convenience cans) would have to be carried out with the belljar environment representative of the PCV under regulatory NCT. This action would also be necessary to ensure that chemical reactions unknown in the thermal environment of a storage vault are not stimulated in the higher temperatures associated with regulatory NCT.

\section{$\underline{\text { RAM Cans Not at Steady State }}$}

In the event that steady state conditions are not defensible for the RAM stored within food-pack cans, longer test duration will be necessary. In addition, lid deflection measurements will be necessary after the measurement of leak rate to discern any increase in can pressure during the belljar test. The duration of the belljar test may need to be longer than the duration of the planned shipment window to demonstrate that conditions within the can upon arrival at the destination are within acceptable limits for flammable gas combustion. Analysis of gasses accumulated within the belljar could be used to reduce the assumption of stoichimetric hydrogen and oxygen composition. This treatment is somewhat like what must be carried out for Test Category payloads for shipment in the TRUPACT-II package. $^{[8]}$

\section{NCT Vibration}

Empirical data from SRS surveillance of plutonium-bearing RAM in storage has shown that storage-can lid deflection (bulge or dish) may change from one stable value to another. ${ }^{[3]}$ This indicates a fundamental change either in the closure seal or in the chemistry within the can perhaps as a result of handling. Clearly, storage conditions do not include the influence of overthe-road vibration associated with NCT. Perhaps belljar testing of gas leakage from storage cans could be carried out on an NCT-energized shaker table to answer the question. 


\section{$\underline{\text { SST Loss of Cooling Accident (LOCA) }}$}

The conveyance used for shipment of plutonium packages within the DOE complex is a well-insulated tractor trailer known as the Safe Secure Trailer (SST). During normal SST operation, the interior environment of the trailer is maintained below a set temperature in accordance with the ambient temperature prescribed in 10 CFR 71.71 for NCT. Environmental control is achieved through the SST's primary and backup cooling systems.

Loss of cargo cooling during transportation of plutonium packages within an SST is beyond the design basis of RAM packages, but nevertheless a possibility. A simple and conservative method of analysis evaluated the 9975 package under a loss of cooling event within an SST. ${ }^{[9]}$ The response of the 9975 package demonstrated that special measures are not normally needed because of the relatively low thermal payload limit. For a maximum heat load of 19 watts, payload temperature increases at roughly $114^{\circ} \mathrm{F} /$ hour. Normally the critical thermal restriction for the 9975 package is the temperature of the cane fiberboard. However, for payloads of unknown moisture content, perhaps process-scrap materials including myriad impurities, the thermal limit may become the temperature of the payload to avoid initiating previously unknown and hence, unevaluated chemical reactions. Consequently, loss of cargo cooling within an SST may need consideration, and special preventative or mitigative measures may be necessary to avoid potentially unacceptable consequences.

\section{$\underline{\text { Regulatory acceptance }}$}

The evaluation of gas generation presented in this paper is very conservative in that the payload solids were assumed to displace zero volume. Additional conservatism is present in the assumption that generated gasses are hydrogen and oxygen in stoichiometric proportions. Oxygen gas is not a direct result of radiolysis of water, and because of its inherent tendency to combine chemically with materials not already oxidized, only a fraction of the liberated oxygen gas will be available to support combustion.

The structural capacities of the containment vessels and their closures have been demonstrated statically by analysis and by testing. Dynamic capacities have been demonstrated analytically but not by testing. An actual detonation test may be necessary to satisfy regulatory packaging authorities.

However, currently proposed in the Federal Register ${ }^{[10]}$ is removal from the HMR of the requirement for double containment of dispersible solid plutonium. Assuming this part of the proposed action to make the HMR more compatible with the International Atomic Energy Agency (IAEA) standard TS-R-1 is successful, a new argument could be made for the value of double containment. Specifically, packaging of uncharacterized gas-generating payloads could benefit from the presence of an SCV. The SCV could be credited for regulatory containment of the payload, while the PCV could be credited for containment and attenuation of a detonation pressure spike. Thereby, a substantial measure of defense-in-depth protection could be established against the consequences of a detonation within a package. This notion would also support the DOE program of maintaining dose to radworkers ALARA by minimizing the hands-on work needed to characterize and possibly re-can the RAM.

\section{ACKNOWLEDGMENTS}

The information contained in this article $\equiv$ developed during the course of work under Contract No. $\square$ AC09-96SR18500 with the U. S. Department of Energy.

\section{REFERENCES}

1 Livingston, R. R., Evaluation of Moisture Limits for Uranium and Plutonium Mixed Oxides to Support On-site Transportation Packaging, WSRC-TR-2000-48, May 2000.

2 Livingston, R. R. and Duffey, J. M., Test Results for Implementation of Hydrogen Getter in the DDF-1 Shipping Package, WSRC-TR-2001-00105, Westinghouse Savannah River Company, Aiken, SC, March 2001.

3 Grim, T. J. and Hensel, S. J., A Plutonium Storage Container Pressure Measurement Technique, WSRC-MS2002-00406, May 2002.

4 Rodrigues, G. C. and Hensel, S. J., A Pre-Shipment Gas Generation Test Using a Bell Jar, WSRC-MS-2002-00406, May 2002.

5 Safety Analysis Report - Packages, 9972-9975 Packages, WSRC-SA-7, Revision 12, Westinghouse Savannah River Company, Aiken, SC, June 2001.

6 Shadday, M. A., A Model of Hydrogen Deflagration/Detonation in a Closed Vessel, WSRC-TR2000-00492, Westinghouse Savannah River Company, Aiken, SC, December 2000.

7 C. A. McKeel, Accident Condition Pressure Capacity of 9975 Series Containment Vessel (U), T-CLC-F-00152, Revision 1, Westinghouse Savannah River Company, Aiken, SC, March 2001.

8 Docket Number 71-9218, Revision 19, TRUPACT-II Authorized Methods for Payload Control, May 2001.

9 Hensel, S. J., Houghtaling, T. K. and VanAlstine, M. N., Thermal Considerations For Transportation Of Radioactive Material Packages Within The Safe Secure Trailer (SST), ASME PVP-Vol. 378, ASME PVP Conference July, 1998, pp. 139-144.

10 Federal Register, 65 FR 44360, July 17, 2000. 